\title{
Evaluation of real time PCR for the detection of Mycobacterium avium subsp. paratuberculosis in faecal samples of cattle
}

\author{
R. K. Chaitanya*1, G. Priyanka ${ }^{2}$ and B. Sreedevi ${ }^{3}$ \\ Department of Veterinary Microbiology, College of Veterinary Science, Tirupati, \\ Sri Venkateswara Veterinary University, \\ Andhra Pradesh-517502, India.
}

Citation: Chaitanya, R.K., Priyanka, G. and Sreedevi, B. 2021. Evaluation of real time PCR for the detection of Mycobacterium avium subsp. paratuberculosis in faecal samples of cattle. J. Vet. Anim. Sci. 52(4):414-417 DOI: https://doi.org/10.51966/jvas.2021.52.4.414-417

Received: 12.09.2021

Accepted: 15.11.2021

Published: 15.12 .2021

\section{Abstract}

The efficiency and suitability of a MAP F57 based SYBR Green qPCR assay for the detection of Mycobacterium avium subsp. paratuberculosis (MAP) using a set of known MAP positive (12) and MAP negative (23) DNA samples that were previously identified by conventional IS 900 PCR were assessed. These DNA samples were isolated in our previous study from faecal samples collected from cattle in the livestock farms under government sector with a previous history of Johne's disease. The MAP F57 qPCR was able to identify all the positive samples accurately and rapidly with $C q$ values ranging from 20-29. The efficiency of $q P C R$ using recombinant plasmid for standard curve was 0.991 and limit of detection was 10 MAP organisms per microlitre of DNA sample.

Keywords: Johne's disease, MAP, qPCR, F57

Running title: Real time PCR detection of Mycobacterium avium subsp. paratuberculosis in cattle faeces

Johne's disease (JD) is characterised by chronic enteritis and wasting in ruminants. The causative agent is Mycobacterium avium subsp. paratuberculosis (MAP). The disease is associated with prolonged course and animals may remain infected sub-clinically for several years with low and intermittent shedding of MAP in faeces (Whittington and Sergeant, 2001). Transmission occurs majorly through faeces which contaminates pastures and farm environment. Animals with clinical disease also shed large number of MAP (106 MAP cells per gram) in the faeces (Eamens et al., 2007). The subclinical form of Johne's disease is difficult to be diagnosed by culture and such animals spread infection silently without manifesting any clinical signs. As the organism is very slow growing and fastidious, PCR based methods for detection have been widely in use and are recommended by OIE (OIE terrestrial manual, 2021).

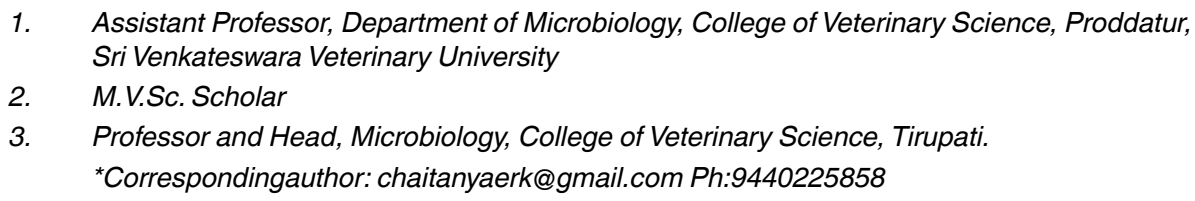

Copyright: (C) 2021 Chaitanya et al. This is an open access article distributed under the terms of the Creative Commons Attribution 4.0 International License (http://creativecommons.org/licenses/by/4.0/), which permits unrestricted use, distribution, and reproduction in any medium, provided the original author and source are credited. 
Most of the diagnostic PCR tests for MAP detection are based on amplification of the MAP specific insertion sequence IS900, which is present in multiple copies in MAP genome and hence offers greater sensitivity (Vansnick et al., 2004). The MAP F57 gene is unique to MAP and absent in other mycobacterial species. Hence PCR assay targeting this gene offers greater specificity (Poupart et al., 1993; Herthnek and Bolske, 2006). Moreover, F57 being a single copy gene is mostly targeted in quantitative real time PCR assays (qPCR) that aim to assess the MAP burden in the clinical samples (Tasara and Stephen, 2005; Irenge et al., 2009). Real time PCR methods offer greater sensitivity than bacterial culture (Schonenbrucher et al., 2008) and can detect very low numbers less than 10 CFU (Mahony and Hill, 2004; Nelli et al., 2008) of MAP.

In this study, a qPCR assay based on SYBR Green chemistry targeting a 195 bp fragment of MAP F57 gene, developed in our previous study (Chaitanya et al., 2019) has been evaluated for its diagnostic efficacy using known MAP positive and negative DNA samples. These DNA samples were isolated in our previous study (Priyanka, 2019) from faecal samples collected from cattle in the government livestock farms with a history of Johne's disease incidence. The DNA extraction kit used was QIAamp DNA stool mini kit (Qiagen). They were identified by IS900 PCR previously as per the method of Vansnick et al. (2004).

A set of twelve MAP IS900 PCR positive DNA samples and 23 PCR negative samples were chosen for evaluating F57 qPCR. The qPCR assays were performed using an Eppendorf Real Plex Master cycler as described by Chaitanya et al. (2019). A standard calibration curve with a series of MAP quantification standards with $10^{9}$ to $10^{\circ}$ copies of recombinant plasmid carrying F57 target sequence (195 bp) was included in each qPCR run. The DNA (20pg/ $\mu \mathrm{L}$ concentration) from known MAP isolate from a previous study (Chaitanya et al., 2015) in Tamil Nadu was used as a positive control. All the samples, standards and positive control were run in duplicate. No template control is included to check the specificity of amplification process.
Standard curve of cycle threshold $(\mathrm{Cq})$ values increasing with increase in dilution of MAP F57 plasmid insert was obtained. The $\mathrm{Cq}$ values plotted against the dilution factor were found to not deviate much from the mean. The $\mathrm{Cq}$ values of standards ranged from 4.2 to 33.1. The least copy number of the plasmid that was able to be detected was $10^{1}$. Slope of the standard curve was -3.297 and the assay

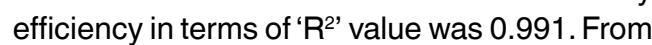
the standard curve, the copy number of F57 plasmid that correspond to each $\mathrm{Cq}$ value and the approximate number of MAP organisms in each microlitre of DNA sample could be calculated. This qPCR technique was able to detect as low as 10 MAP per microlitre of the DNA.

In MAP F57 qPCR all the 12 DNA samples that were positive in IS900 PCR were positive with $\mathrm{Cq}$ values ranging from 20 to 29 . One of the 23 IS900 PCR negative samples was considered to be inconclusive or doubtful in $\mathrm{qPCR}$ with $\mathrm{Cq}$ value 30 and this might be because of high sensitivity of amplification detection in real time PCR when compared to the gel electrophoresis in conventional PCR. Such animals should be tested again after a couple of months with a fresh faecal sample. The $\mathrm{Cq}$ values above 35 were considered as negative because all other 22 samples that were IS900 PCR negative did not show any initiation of amplification curve before $35^{\text {th }}$ cycle. The melt curve analysis confirmed that all the amplicons have acceptable $\mathrm{Tm}$ value of $86.8 \pm 0.2$ indicating the specificity of the assay.

It is evident that this qPCR assay is rapid than conventional PCR. It is suitable for direct detection of MAP in the clinica samples. Developed countries like Australia have adopted real time PCR testing of faecal samples for diagnosis and surveillance of Johne's disease (Plain et al., 2014). However, the assay needs further refinement by inclusion of internal control target for checking the DNA extraction losses and for monitoring PCR amplification conditions. It is well known that DNA extraction procedure may cause reduction in copy number and lead to under estimation of MAP load in the clinical samples. The complex and lipid rich cell wall of MAP results in poor 
DNA recovery and $\mathrm{PCR}$ inhibitors in faeces affect amplification of the target. Assay should be also evaluated using faecal samples spiked with known number of MAP to find out limit of detection in its actual sense.

\section{Summary}

The MAP F57 qPCR assay detected all the 12 IS900 PCR positive DNA samples as positive with $\mathrm{Cq}$ values ranging from 20 to 29 that corresponds to $10^{4}$ MAP copies to 100 copies per microlitre of DNA. The $\mathrm{Cq}$ values above 35 were considered as negative. The qPCR assay is rapid and sensitive than conventional PCR detect as low as 10 MAP per microlitre of the DNA.

\section{Conflict of interest}

The authors declare that they have no conflict of interest.

\section{References}

Chaitanya, R.K., Reddy, Y.K.M. and Arthanari, T. 2015. Strain typing of Mycobacterium avium subsp. paratuberculosis from Tamil Nadu, India based on polymorphisms in MAP1506 locus and IS1311 PCR-REA. Adv. Anim. Vet. Sci. 3: 289-294.

Chaitanya, R.K., Reddy, Y.K.M., Dhinakar Raj, G. and Thangavelu, A. 2019. Quantification of Mycobacterium avium subsp. paratuberculosis from the tissues of challenged mice using SYBR Green real time PCR assay for the assessment of vaccine efficacy. Ind. J. Anim. Res. 53: 944-948.

Eamens, G.J., Whittington, R.J., Turner, M.J., Austin, S.L., Fell, S.A. and Marsh, I.B. 2007. Evaluation of radiometric faecal culture and direct PCR on pooled faeces for detection of Mycobacterium avium subsp. paratuberculosis in cattle. Vet. Microbiol. 125: 22-35.

Herthnek, D. and Bolske, G. 2006. New PCR systems to confirm real time PCR detection of Mycobacterium avium subsp. Paratuberculosis. BMC Microbiol. 6: 87.
Irenge, L.M., Walravens, K., Govaerts, M., Godfroid, J., Roseels, V., Huygen, K. and Gala, J.L. 2009. Development and validation of triplex real-time PCR for rapid detection and specific identification of $M$. avium subsp. paratuberculosis in fecal samples. Vet. Microbiol. 136: 166172.

Mahony, J.O. and Hill, C. 2004. Rapid real time PCR assay for detection and quantification of Mycobacterium avium subsp. paratuberculosis in artificially contaminated milk. Appl. Environ. Microbiol. 70: 4561-4568.

Nelli, R.K., Graham, E., Dunham, S.P., and Taylor, D.J. 2008. Real time PCR identification of Mycobacterium avium subsp. Paratuberculosis in ovine and bovine tissues. Vet. Rec. 163: 422-423.

OIE world organization for animal health. Manual of diagnostic tests and vaccines for terrestrial animals online. 2021. Chapter 3.1.15. Paratuerculosis (Johne's disease).

Plain, K.M., Marsh, I.B., Waldron, A.M., Galea, F., Whittington, AM., Saunders, V.F., Begg, D.J., De Silva, K., Purdie, A.C. and Whittington, R.J. 2014. High-Throughput direct fecal PCR assay for detection of Mycobacterium avium subspecies paratuberculosis in sheep and cattle. J. Clin. Microbiol. 52 (3): 745-757.

Poupart, P., Cone, M., Van Heuverswyn, H. and Cocito, C. 1993. Preparation of a specific RNA probe for detection of Mycobacterium paratuberculosis and diagnosis of Johne's disease. J. Clin. Microbiol. 31: 1601-1605.

Priyanka, G. 2019. Molecular detection and characterization of Mycobacterium avium subsp. Paratuberculosis in ruminants of Andhra Pradesh. M.V.Sc. thesis submitted to Sri Venkateswara Veterinary University, Tirupati, p41-46.

Schonenbrucher, H., Abdulmawjood, A., Failing, K. and Bulte, M. 2008. New 
triplex realtime PCR assay for detection of Mycobacterium avium subsp. paratuberculosis in bovine feces. Appl. Environ. Microbiol. 74: 2751-2758.

Tasara, T., and Stephen, R. 2005. Development of an F57 sequence based real-time PCR assay for detection of Mycobacterium avium subsp. paratuberculosis in milk. Appl. Environ. Microbiol. 71:5957-5968.

Vansnick, E.L., De Rijk, O.P., Vercammen, F., Geysen, D., Rigouts, L. and Portaels,
F. 2004. Newly developed primers for the detection of Mycobacterium avium subsp. paratuberculosis. Vet. Microbiol. 100:197-204.

Whittington, R.J. and Sergeant, E.S. 2001. Progress towards understanding the spread, detection and control of Mycobacterium avium subspecies paratuberculosis in animal populations. Aust. Vet. J. 79: 267-278. 